\title{
Editorial
}

\section{Layered Double Hydroxides (LDHs)}

\author{
Roberto Pizzoferrato *(D) and Maria Richetta *(i) \\ Department of Industrial Engineering, Università degli Studi di Roma Tor Vergata, 00133 Rome, Italy \\ * Correspondence: pizzoferrato@uniroma2.it (R.P.); richetta@uniroma2.it (M.R.)
}

Received: 4 December 2020; Accepted: 7 December 2020; Published: 9 December 2020

Hydrotalcite, the first natural mineral belonging to the family of layered materials, was discovered in Sweden by Hochstetter in 1842, but it was not until 1930 that the first study on its synthesis, solubility, stability, and structure was carried out by Feitknecht.

Since then, the family of layered materials has become wider and wider, and also been variously named over time. Layered Double Hydroxides (LDHs), Layered Hydroxicarbonates, Hidrotalcite-like Materials, Anionic Clays, etc., are just some of the many examples, although none of them are sufficiently exhaustive and reflect the current situation. Regardless of the denomination, these materials are not as naturally occurring as cationic clays are, nonetheless they are easy to prepare and are low-cost.

What made and makes these materials extremely interesting is the fact that the nature of the layer cations can be varied within a wide selection, and the nature of the interlayer anion can be chosen, almost at will, between organic and inorganic anions, polymetalates, simple anionic coordination compounds, etc. Like the cationic clays, they can be pillared and, even more importantly, the interlayer anions can be easily exchanged. This property increases the possible applications and opens new routes to the synthesis of derivatives. Furthermore, unlike cationic clays, they are able to recover the lamellar structure after undergoing thermal decomposition. This property can also be used as a synthesis technique.

Since the pioneering work of Feitknecht, LDHs have been synthesized by direct and indirect methods, such as coprecipitation, hydrothermal growth, sol-gel synthesis, soft chemistry, electrochemical synthesis, anion exchange, and those in which LDHs are used as precursors.

The opportunities offered by these properties are extremely ample, and it is precisely for this reason that the applications of LDHs are constantly growing. The main areas of interest range from renewable energy production to water purification and remediation, including functionalized materials for piezoelectric nanogenerators and gas sensing. Great attention is paid to biomedical applications and to the synthesis of hybrid smart nanocomposites, which involve expanding sectors such as drug-delivery, food packaging and safety.

Within this Special Issue, eight articles are collected, and are divided between synthesis techniques [1-3], applications [4-6], and review works [7,8].

The first work, related to the synthesis of $\mathrm{Mg}-\mathrm{Al}, \mathrm{Ca}-\mathrm{Al}, \mathrm{Zn}-\mathrm{Al}$ and $\mathrm{Cu}-\mathrm{Al} \mathrm{LDHs}$, is the one carried out by Barnard and Labuschagne [1]. The authors, in order to propose a green synthesis technique, implement the wet mechanochemical method through the use of a Netzsch LME 1 horizontal bead mill, designed "ad hoc" for wet grinding applications. In this way they are able to eliminate the production of salt-rich effluent and the control of $\mathrm{pH}$. Furthermore, an aging phase allows a better conversion of raw materials into LDH structures, as well as a morphological improvement of the structures. Another notable point is that the selected mill can be easily scaled up for the production of large quantities of LDH products.

In addition, in the work proposed by Gevers and Labuschagné [2], the authors take care to adopt an environmentally friendly synthesis. In particular, they present the results obtained through the hydrothermal synthesis of hydrocalumite $(\mathrm{HC})$ and $\mathrm{Al}(\mathrm{OH})_{3}$ in water, examining the parameters 
that impact the formation process of $\mathrm{CaAl}-\mathrm{OH}-\mathrm{LDH}$, i.e., reaction temperature and time, molar ratio, mixing ratio, water/solid ratio, and morphology/crystallinity of reactants. They show that the use of oxides and hydroxides as starting materials allows one to reduce the production of polluting waste streams, while permitting one to obtain $\mathrm{HC}$ formation in each experiment conducted. Furthermore, the carbonate content present in $\mathrm{CaAl}-\mathrm{OH}-\mathrm{LDH}$ essentially comes from calcite or $\mathrm{Al}(\mathrm{OH})_{3}$, such as surface adsorbed carbonate species, rather than from air. Regarding the significant parameters, the authors show how the use of a low water/solid ratio, an increase in time and temperature of reaction, the use of amorphous and large surface $\mathrm{Al}(\mathrm{OH})_{3}$, as well as a stoichiometric ratio calcium/aluminium, favor the formation of katoite, and the purity of HC.

In Reference [3], Valeikiene et al. present a study on the reconstruction peculiarities of $\mathrm{Mg}_{2-x} \mathrm{M}_{\mathrm{x}} / \mathrm{Al}_{1}$ $(\mathrm{M}=\mathrm{Ca}, \mathrm{Sr}, \mathrm{Ba}) \mathrm{LDH}$ made by means of the indirect sol-gel synthesis route. In particular, the results of two different sol-gel synthesis procedures are presented. First, the mixed metal oxides (MMO) are obtained by directly heating the precursor $\mathrm{Mg}(\mathrm{M})-\mathrm{Al}-\mathrm{O}$ to $(650,800,950){ }^{\circ} \mathrm{C}$. All the samples obtained, once immersed in water at $50{ }^{\circ} \mathrm{C}$, were reconstructed to $\mathrm{Mg}_{2-\mathrm{x}} \mathrm{M}_{\mathrm{x}} / \mathrm{Al}_{1} \mathrm{LDH}$. However, the spinel phases remained as impurities and a small quantity of carbonates formed. During the second phase, the reconstructed LDHs were heated to the same temperatures as before. The composition, morphology, and surface properties of these MMOs were then compared with the analogues obtained by the first method. The results showed that the Ca and Sr substituted MMOs contain multiple side phases. The most interesting result, however, lies in the "memory effect" exhibited by the microstructures of MMOs reconstructed from sol-gel-derived LDH, i.e., the microstructural properties of the MMOs were found to be practically identical to those of LDH and, moreover, independent of the annealing temperature.

The other five papers explore the wide field of the present and potential applications of LDHs, and provide some interesting examples of how the many peculiar properties of these materials can be exploited in very different sectors.

In Reference [4], Tampieri et al. address the search for renewable energy sources by investigating the properties of LDHs as catalysts for the synthesis of biofuels. The authors report a microwave-assisted batch process for the neat aldol condensation of furfural and acetone over Mg:Al hydrotalcites (HTs) and derivatives. Differently from previous studies, they prepared HTs in the laboratory and carried out calcination and rehydration to produce mixed metal oxides (MMOs) and meixnerite-like (MX) LDHs, respectively. This allowed them to study how the catalyst activity and selectivity varied over the different derivatives. In addition, an exhaustive analysis of the influence of other reaction parameters was performed. MX resulted in by far the most active catalyst, followed by MMO and HT. Interestingly, HT was generally reported as inactive. In comparison with conventional heating, microwave-assisted condensation is more selective and faster, and also works well at temperatures below $100{ }^{\circ} \mathrm{C}$, even though it requires a longer reaction time.

The capability to exchange interlayer anions is another remarkable characteristic of LDHs, and can be exploited to either adsorb or release anionic species from or into the environment. In Reference [5], Cardinale et al. explore the adsorption properties of $\mathrm{MgAl}-\mathrm{CO}_{3}$ and $\mathrm{NiAl}-\mathrm{NO}_{3} \mathrm{LHDs}$ for the removal of some heavy metals from real wastewater, supplied by a galvanic treatment company. The authors found a certain degree of selectivity of these LDHs, in that $\mathrm{Cr}(\mathrm{VI})$ is more efficiently removed by the NiAl LDH through an exchange with the interlayer nitrate. On the other hand, $\mathrm{Fe}(\mathrm{III})$ and $\mathrm{Cu}(\mathrm{II})$ are removed in higher amounts by the $\mathrm{MgAl} \mathrm{LDH}$, probably through a substitution with $\mathrm{Mg}$. However, other mechanisms, such as sorption on the $\mathrm{OH}^{-}$functional groups, surface complexation, and/or precipitation on the surface of $\mathrm{LDH}$, could not be completely excluded. In the first case, the ionic concentration of $\mathrm{Cr}(\mathrm{VI})$ is lowered to a value close to the legal limit, while the concentrations of $\mathrm{Fe}(\mathrm{III})$ and $\mathrm{Cu}(\mathrm{II})$ are reduced well below the legal limit.

In Reference [6], Pavel et al. report the incorporation of Curcumin (CR) in the $\mathrm{Zn}_{3} \mathrm{Al}-\mathrm{LDH}$ matrix in order to investigate the release of anionic species for application in drug delivery. The promising antioxidant activity of this natural polyphenol is hindered by its poor solubility 
in water at neutral $\mathrm{pH}$, which could be overcome by the incorporation of suitable nanocarriers, such as LDHs. Specifically, the authors used $\mathrm{Zn}_{3} \mathrm{Al}-\mathrm{LDH}$, in place of the commonly studied $\mathrm{Mg}_{\mathrm{x}} \mathrm{Al}-\mathrm{LDH}$, to increase the antioxidant activity due to the antiseptic properties of $\mathrm{Zn}$. By performing incorporations in both a pristine and a reconstructed matrix, with the addition of $C R$ either as an aqueous alkaline solution (Aq) or as an ethanolic solution (Et), the authors investigated the conditions for the lowest degradation and highest release of CR. They found that reconstruction with a CR-ethanolic solution, which does not restore the layered LDH structure, is the preferable method to obtain CR-loaded $\mathrm{Zn}_{3} \mathrm{Al}$ solids from LDH precursors.

Finally, two review papers conclude this Special Issue by reporting on some of the many different applications that derive from the capability of LDHs to combine with organic polymers and form hybrid organic/inorganic nanocomposites materials. In Reference [7], Mohapi et al. review and compare the role of LDHs and natural nanoclays in forming polymer-based materials for water purification systems. Specific attention is paid to the preparation methods and the corresponding influence of external parameters in the adsorption process. A solution blending technique and in situ polymerization strategies seem to provide a better dispersion of clay layers in the polymer matrix compared to the melt blending technique. However, melt blending is considered more industrially viable as well as eco-friendly, and shows high economic potential. In Reference [8], Mochane et al. review the utilization of LDHs as nanofillers in polymer-based matrices to improve mechanical and thermal stability, flame retardancy and gas barrier characteristics. While these properties are key factors in a wide field of use, such as in food packaging and safety, other applications, including energy, water purification, gas sensing, biomedical and piezoelectric nanogenerators, are also reviewed. The synergy between polymers and LDHs with peculiar characteristics is especially discussed. It is also pointed out that there are few studies investigating the thermal conductivity of LDHs in combination with other well-known conductive fillers, such as expanded graphite, carbon nanotubes, carbon black, and carbon fibers, which could widen the applications of LDHs nanocomposites.

In summary, we believe that this Special Issue highlights some of the recent lines of a topic as broad as a peculiar type of layered nanomaterial with a large range of possible compositions, many different methods of synthesis and functionalization, several interesting physicochemical properties, and ample opportunities for present and potential application. The present articles show that remarkable progress has been and is still being made on all these aspects, to allow the considering of LDHs as one of the most interesting and versatile inorganic materials.

We would like to thank all authors who have contributed for having submitted manuscripts of such excellent quality. We also wish to thank the large number of reviewers and the editorial staff at Crystals, especially the Section Managing Editor, for the fast and professional handling of the manuscripts and for the help provided throughout.

Funding: This research received no external funding.

Conflicts of Interest: The authors declare no conflict of interest.

\section{References}

1. Barnard, A.A.; Labuschagné, F.J.W.J. Exploring the Wet Mechanochemical Synthesis of Mg-Al, Ca-Al, Zn-Al and $\mathrm{Cu}-\mathrm{Al}$ Layered Double Hydroxides from Oxides, Hydroxides and Basic Carbonates. Crystals 2020, 10, 954. [CrossRef]

2. Gevers, B.R.; Labushagné, F.J.W.J. Green Synthesis of Hydrocalumite (CaAl-OH-LDH) from $\mathrm{Ca}(\mathrm{OH})_{2}$ and $\mathrm{Al}(\mathrm{OH})_{3}$ and the Parameters That Influence Its Formation and Speciation. Crystals 2020, 10, 672. [CrossRef]

3. Valeikiene, L.; Roshchina, M.; Grigoraviciute-Puroniene, I.; Prozorovich, V.; Zarkov, A.; Kareiva, A. On the Reconstruction Peculiarities of Sol-Gel Derived $\mathrm{Mg}_{2-\mathrm{x}} \mathrm{M}_{\mathrm{x}} / \mathrm{Al}_{1}(\mathrm{M}=\mathrm{Ca}, \mathrm{Sr}, \mathrm{Ba})$ Layered Double Hydroxides. Crystals 2020, 10, 470. [CrossRef]

4. Tampieri, A.; Lilic, M.; Costantini, M.; Medina, F. Microwave-Assisted Aldol Condensation of Furfural and Acetone over Mg-Al Hydrotalcite-Based Catalysts. Crystals 2020, 10, 833. [CrossRef] 
5. Cardinale, A.M.; Carbone, C.; Consani, S.; Fortunato, M.; Parodi, N. Layered Double Hydroxides for Remediation of Industrial Wastewater from a Galvanic Plant. Crystals 2020, 10, 443. [CrossRef]

6. Pavel, O.D.; Şerban, A.; Zăvoianu, R.; Bacalum, E.; Bîrjega, R. Curcumin Incorporation into $\mathrm{Zn}_{3} \mathrm{Al}$ Layered Double Hydroxides-Preparation, Characterization and Curcumin Release. Crystals 2020, 10, 244. [CrossRef]

7. Mohapi, M.; Shale Sefadi, J.; Mochane, M.J.; Magagula, S.I.; Lebelo, K. Effect of LDHs and Other Clays on Polymer Composite in Adsorptive Removal of Contaminants: A Review. Crystals 2020, 10, 957. [CrossRef]

8. Mochane, M.J.; Magagula, S.J.; Shale Sefadi, J.; Rotimi Sadiku, E.; Mokhena, T.C. Morphology, Thermal Stability, and Flammability Properties of Polymer-Layered Double Hydroxide (LDH) Nanocomposites: A Review. Crystals 2020, 10, 612. [CrossRef]

Publisher's Note: MDPI stays neutral with regard to jurisdictional claims in published maps and institutional affiliations.

(C) 2020 by the authors. Licensee MDPI, Basel, Switzerland. This article is an open access article distributed under the terms and conditions of the Creative Commons Attribution (CC BY) license (http://creativecommons.org/licenses/by/4.0/). 